\title{
Benefits of an Oxygen Reservoir Cannula versus a Conventional Nasal Cannula during Exercise in Hypoxemic COPD Patients: A Crossover Trial
}

\author{
Rainer Gloeckl ${ }^{a} \quad$ Inga Heinzelmann ${ }^{a} \quad$ Maximilian Matthaei ${ }^{b} \quad$ Stella Seeberg ${ }^{a}$ \\ Thomas Damisch $^{\mathrm{a}}$ Andreas Jerrentrup ${ }^{\mathrm{b}}$ Klaus Kenn ${ }^{\mathrm{a}}$

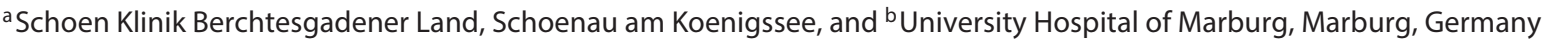

\section{Key Words}

Chronic obstructive pulmonary disease · Long-term oxygen therapy · Oxymizer · Nasal cannula

\begin{abstract}
Background: The Oxymizer ${ }^{\circledR}$ is a special nasal cannula that provides a higher luminal diameter in combination with an incorporated oxygen $\left(\mathrm{O}_{2}\right)$ reservoir. It is assumed that a higher $\mathrm{O}_{2}$ concentration can be delivered breath by breath in order to increase oxygenation. Objective: We aimed to investigate the effects of the Oxymizer on endurance time in comparison to a conventional nasal cannula (CNC). Methods: Forty-three patients with severe chronic obstructive pulmonary disease (COPD, age $60 \pm 9$ years, $\mathrm{FEV}_{1} 37 \pm 16 \%$ pred.) and indications for LTOT were recruited during pulmonary rehabilitation for this cross-over study. After an initial maximal incremental cycle test, all patients performed 4 cycling endurance time tests at $70 \%$ of their peak work rate (twice with the Oxymizer and twice with a CNC, in reverse order). Results: The endurance time was significantly higher when patients cycled while using the Oxymizer in comparison to while using the CNC [ $858 \pm 754$ vs. $766 \pm 652$ s; betweengroup difference $92 \mathrm{~s}$ (95\% confidence interval 32-152), $\mathrm{p}<$ $0.001]$. In addition to a longer cycling duration, $\mathrm{O}_{2}$ saturation at isotime was significantly higher with the Oxymizer (93.5 \pm 5.4 vs. $90.4 \pm 5.3 \% ; p=0.027$ ). Furthermore, there was a pos-
\end{abstract}

itive correlation ( $r=0.427, \mathrm{p}=0.002$ ) between the $\mathrm{O}_{2}$ flow rate and improvements in the constant work rate test, showing greater improvements in favor of the Oxymizer in patients with a higher demand for $\mathrm{O}_{2}$ ( $\geq 4$ liters $/ \mathrm{min}$ ). Conclusion: We show that $\mathrm{O}_{2}$ delivery via the Oxymizer is superior to a CNC with regard to endurance capacity and oxygenation during exercise in patients with severe COPD. It seems that patients with a higher demand for $\mathrm{O}_{2}(\geq 4$ liters $/ \mathrm{min}$ ), in particular, may benefit more from the use of the Oxymizer.

(c) 2014 S. Karger AG, Basel

\section{Background}

Long-term oxygen $\left(\mathrm{O}_{2}\right)$ therapy (LTOT) is clearly indicated and recommended as a part of routine clinical practice in patients with hypoxemic chronic obstructive pulmonary disease (COPD) $[1,2]$. The benefits of LTOT in patients with COPD are well known. LTOT reduces hospitalizations and the risk of comorbidities and prolongs survival $[3,4]$. The rationale for supplemental $\mathrm{O}_{2}$ during exercise in hypoxemic COPD patients is related to improved peripheral muscle oxygenation [5] and exercise capacity [6] as well as decreased symptoms of dyspnea [7], possibly allowing them to train at higher intensities [8]. However, the ideal kind of $\mathrm{O}_{2}$ application has not yet been clarified [9]. The most popular device in clinical practice

\section{KARGER}

E-Mail karger@karger.com

www.karger.com/res
C 2014 S. Karger AG, Basel

0025-7931/14/0885-0399\$39.50/0
Rainer Gloeck

Department of Respiratory Medicine

Schoen Klinik Berchtesgadener Land

DE-83471 Schoenau am Koenigssee (Germany)

E-Mail rainer.gloeckl@gmx.de 


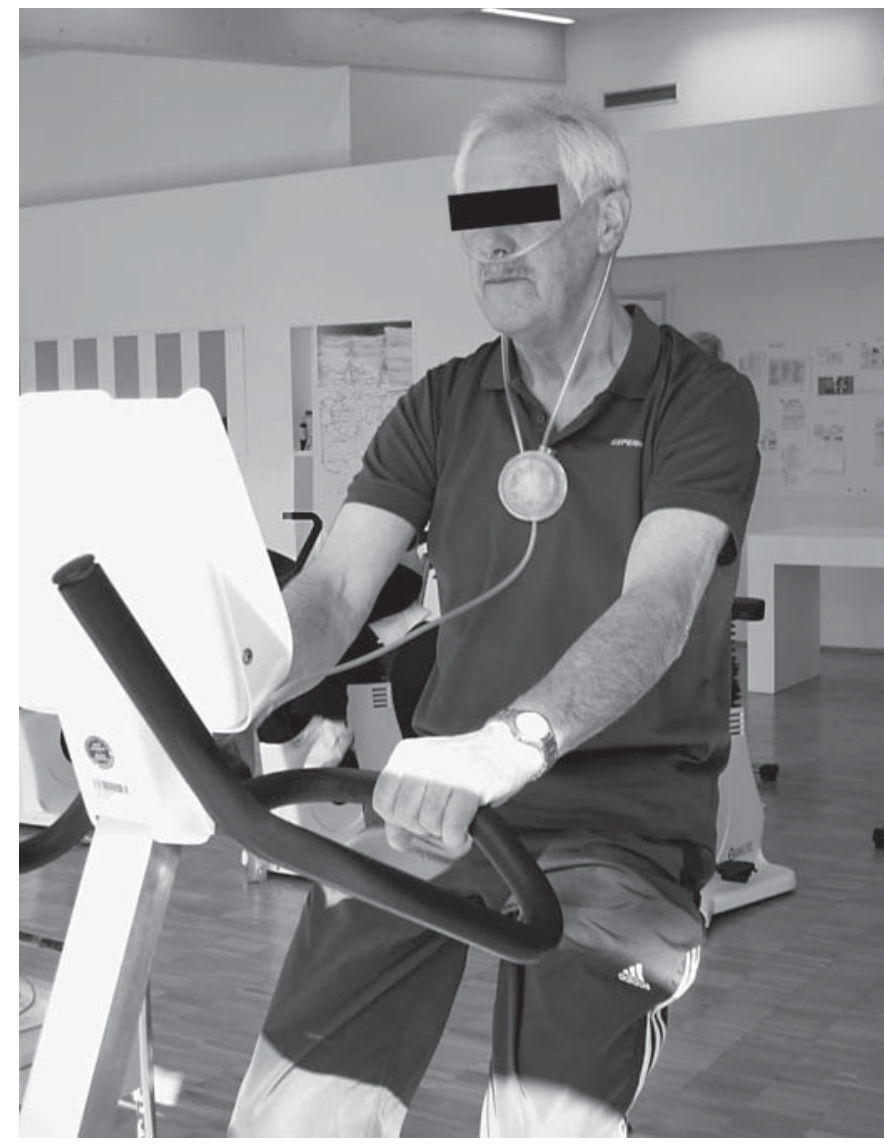

Fig. 1. A patient during the CWRT receiving $\mathrm{O}_{2}$ supplementation with the Oxymizer (his written consent was received for publication of this photograph).

is the conventional nasal cannula (CNC). The Oxymizer ${ }^{\circledR}$ device (Inovo Inc., Fla., USA) was first developed in the early 1980 s. It contains a flow-reducing $\mathrm{O}_{2}$ reservoir within the cannula (fig. 1). The pendant is covered within a hard, plastic, circle-shaped chamber and is worn in a sternal position under or on top of the clothing. The Oxymizer pendant stores $\mathrm{O}_{2}$ during exhalation and delivers an enriched $\mathrm{O}_{2}$-bolus in addition to continuous flow upon inhalation. Thus patients' oxygenation may be improved [10] and/or $\mathrm{O}_{2}$ flow rates can be decreased without compromising the level of oxygenation [11]. Up to now, most studies have investigated the effects of the initial, less-sophisticated version of the Oxymizer; in the late 1980s, they were limited by small sample sizes and/or examined patients' oxygenation only at rest [11-16]. We aimed to investigate the potential benefits of the advanced Oxymizer in comparison to a CNC during exercise in an adequately powered sample size of hypoxemic patients with COPD.

\section{Methods and Materials}

\section{Patients}

All patients admitted for a 3-week inpatient pulmonary rehabilitation program with spirometry-proven COPD (Global Initiative for Obstructive Lung Disease stage IV) and on established LTOT (a flow rate $\geq 2$ liters/min at rest or during activity) were eligible for participation in the study. They were included after giving their written informed consent. Exclusion criteria consisted of common known absolute and relative contraindications for cardiopulmonary exercise testing [17].

\section{Study Design}

Consecutive patients admitted to our pulmonary rehabilitation program (content described elsewhere) [18] between March 2012 and December 2013 were invited to participate in this randomized cross-over study. Due to the study design, it was not possible to blind patients and the investigators who performed the constant work rate tests (CWRTs) to the $\mathrm{O}_{2}$ device. However, the researchers who performed the final data analyses were blinded to group allocation as the intervention type was encoded by numbers.

To start, all patients performed a standardized, symptom-limited incremental cycle test (Cardiomed Bike, Proxomed Medical, Alzenau, Germany), beginning at $25 \mathrm{~W}$, with an increase of 10 $\mathrm{W} / \mathrm{min}$ until exhaustion [17]. Patients were highly encouraged to reach their maximal work rate. Peak work rate (PWR) was defined as the highest work rate that subjects were able to maintain for the previous $60 \mathrm{~s}$. The next day, the patients consecutively performed a sequence of 4 cycling CWRTs at 70\% of their initial PWR [19]. On day 1 and 2 after the incremental cycle test, patients performed 1 CWRT using a CNC or the Oxymizer after $24 \mathrm{~h}$ in random order. One week later, they repeated the 2 CWRTs again on 2 consecutive days at the same work load using $\mathrm{CNC}$ and Oxymizer in reverse order (see online suppl. fig.1; for all online suppl. material, see www.karger.com/doi/10.1159/000368165).

Before each CWRT, patients were instructed to cycle as long as possible at their given work load and at $\geq 50$ revolutions $/ \mathrm{min}$. Patients were told to inhale through the nose and to exhale using pursed-lips breathing, if possible. Settings of the cycle ergometer like seat height or handlebar position were noted and were kept the same for all tests. Before each CWRT, patients initially rested for $10 \mathrm{~min}$ sitting on the bicycle while breathing $\mathrm{O}_{2}$ via the nasal cannula that was used during the test. Patients then were motivated every minute by encouragements from the investigator like 'Well done, 'try to go on' and 'Perfect, you can make it' to ensure that external motivation at each CWRT was similar. If patients were able to cycle for $>30 \mathrm{~min}$, intensity was then increased by $10 \mathrm{~W}$ every 5 min until exhaustion.

This study was approved by the Bavarian Ethics Committee (ID12019) and listed in the Clinical Trials Registry (www.clinicaltrials.gov; NCT01713413).

\section{Hypothesis}

Our primary hypothesis was that, in comparison to $\mathrm{CNC}$, the use of the Oxymizer by hypoxemic COPD patients during CWRT will prolong endurance time to a clinically relevant amount.

\section{Randomization Procedure}

Allocation concealment was administered by a computer-generated randomization procedure using permuted blocks with a length of 6 numbers and a 1:1 ratio which was revealed after the pa- 
tient was included in the study. The decision to accept or reject a participant was made with no knowledge of the next assignment in the sequence.

\section{Outcomes and Measurements}

The primary outcome parameter was endurance time achieved during CWRT. Partial pressure of $\mathrm{O}_{2}\left(\mathrm{PaO}_{2}\right)$, partial pressure of carbon dioxide $\left(\mathrm{PaCO}_{2}\right)$ and symptoms of dyspnea and leg fatigue at the end of CWRT were determined as secondary outcome parameters. $\mathrm{PaO}_{2}$ and $\mathrm{PaCO}_{2}$ were assessed by blood gas analysis (ABL 820 , Radiometer $\mathrm{GmbH}$, Willich, Germany) taken from the hyperemic earlobe. 'Isotime' was defined as the duration of the shortest CWRT between the tests with the Oxymizer and the CNC. Values for heart rate and $\mathrm{O}_{2}$ saturation $\left(\mathrm{SpO}_{2}\right)$ at isotime were retrospectively determined by analyzing the continuously recorded data of the SenTec ${ }^{\circledR}$ device (SenTec AG, Therwil, Switzerland), with patients being linked to the device via an ear clip during all CWRTs.

The first blood gas analyses were made at rest while the patient was sitting on the cycle ergometer. During the CWRT, patients were asked to give a brief signal when they come close to exhaustion, so the investigator could prepare to take the second blood gas measurement in the last seconds of cycling. Before and directly at the end of the CWRT, patients were asked to rate the intensity of dyspnea symptoms and leg fatigue on the modified Borg scale (0-10) [20].

Lung function was measured on admission by Master Screen Body Plethysmograph (Jaeger, Wuerzburg, Germany) in accordance with ATS guidelines [21]. To determine fat-free mass index, body composition was measured by NutriGuard MS (Data Input Body Composition, Poecking, Germany).

\section{Sample Size Calculation}

To detect a minimal important difference of $105 \mathrm{~s}$ at the CWRT [22] between the two types of $\mathrm{O}_{2}$ application, assuming a standard deviation of $238 \mathrm{~s}$, a statistical power of $80 \%$ and a risk for a type 1 error $(\alpha)<5 \%$, a sample size of 43 patients in total would be needed.

\section{Statistical Analysis and Missing Data}

Data are presented as mean and standard deviation or mean and $95 \%$ confidence interval (CI) unless otherwise stated. Mean values of both CWRTs with CNC and the Oxymizer were taken for final analysis, respectively. Since all values were normally distributed, intragroup comparison was carried out by using a paired Student $t$ test. An unpaired t test was used to analyze normally distributed subgroup differences between the 'Lowflower' and 'Highflower' group (see online suppl. table 1). The level of significance was set at $\mathrm{p} \leq 0.05$. Missing data were treated as follows. Blood gas samples were invalid in 3 patients at the end of the CWRT with the CNC and in 2 patients during Oxymizer use, respectively. These 5 patients were excluded from the secondary outcome analysis of capillary blood gases at the end of the CWRT. All other data were available. Data analysis was performed using PASW Statistics v18.0 (Chicago, Ill., USA). Figures were designed by GraphPad Prism v5 (San Diego, Calif., USA).

\section{Results}

Forty-five patients were enrolled in this study. After the first CWRT, 2 patients quit the study at their own request because the study design was too stressful for them.
Table 1. Baseline characteristics

\begin{tabular}{|c|c|}
\hline \multicolumn{2}{|l|}{ Parameters } \\
\hline Number of patients & 43 \\
\hline Age, years & $60.1 \pm 8.9$ \\
\hline Female, n (\%) & $21(49)$ \\
\hline $\mathrm{BMI}, \mathrm{kg} / \mathrm{m}^{2}$ & $24.9 \pm 5.3$ \\
\hline BODE index & $5.1 \pm 1.9$ \\
\hline CAT score & $22.8 \pm 6.3$ \\
\hline FFMI & $19.0 \pm 3.1$ \\
\hline \multicolumn{2}{|l|}{ Drugs on admission, $\mathrm{n}(\%)$} \\
\hline LABA & $41(95)$ \\
\hline LAMA & $35(81)$ \\
\hline Theophyllin & $5(12)$ \\
\hline ICS & $38(88)$ \\
\hline Oral corticosteroids & $6(14)$ \\
\hline $\mathrm{O}_{2}$-demand at rest, $1 / \mathrm{min}$ & $1.9 \pm 1.3$ \\
\hline $\mathrm{O}_{2}$-demand during activity or exercise, $1 / \mathrm{min}$ & $3.6 \pm 1.3$ \\
\hline $\mathrm{PaO}_{2}$ at rest breathing room air, $\mathrm{mm} \mathrm{Hg}$ & $55.8 \pm 5.9$ \\
\hline $\mathrm{PaCO}_{2}$ at rest breathing room air, $\mathrm{mm} \mathrm{Hg}$ & $41.7 \pm 7.5$ \\
\hline $\begin{array}{l}\mathrm{PaO}_{2} \text { at rest breathing } \mathrm{O}_{2} \text { with the } \mathrm{CNC}, \mathrm{mm} \mathrm{Hg} \\
\left(\mathrm{O}_{2} \text { flow rate } 2.5 \pm 0.8 \text { liters } / \mathrm{min}\right)\end{array}$ & $72.5 \pm 14.3$ \\
\hline $\begin{array}{l}\mathrm{PaCO}_{2} \text { at rest breathing } \mathrm{O}_{2} \text { with the } \mathrm{CNC}, \mathrm{mm} \mathrm{Hg} \\
\quad\left(\mathrm{O}_{2} \text { flow rate } 2.5 \pm 0.8 \text { liters } / \mathrm{min}\right)\end{array}$ & $41.3 \pm 7.1$ \\
\hline $\begin{array}{l}\mathrm{PaO}_{2} \text { at rest breathing } \mathrm{O}_{2} \text { with the } \mathrm{OXY}, \mathrm{mm} \mathrm{Hg} \\
\left(\mathrm{O}_{2} \text { flow rate } 2.5 \pm 0.8 \text { liters } / \mathrm{min}\right)\end{array}$ & $78.1 \pm 18.0^{*}$ \\
\hline $\begin{array}{l}\mathrm{PaO}_{2} \text { at rest breathing } \mathrm{O}_{2} \text { with the } \mathrm{OXY}, \mathrm{mm} \mathrm{Hg} \\
\left(\mathrm{O}_{2} \text { flow rate } 2.5 \pm 0.8 \text { liters } / \mathrm{min}\right)\end{array}$ & $41.2 \pm 7.7$ \\
\hline PWR, W & $67 \pm 23$ \\
\hline $70 \%$ PWR, W & $48 \pm 19$ \\
\hline $\mathrm{FEV}_{1}$, liters & $1.1 \pm 0.6$ \\
\hline $\mathrm{FEV}_{1}, \%$ pred. & $37.5 \pm 16.9$ \\
\hline TLC, liters & $8.9 \pm 1.6$ \\
\hline TLC, $\%$ pred. & $146.9 \pm 28.0$ \\
\hline $\mathrm{RV}$, liters & $6.2 \pm 1.7$ \\
\hline RV, \% pred. & $283.6 \pm 82.6$ \\
\hline DLCO, \% pred. & $29 \pm 14$ \\
\hline
\end{tabular}

BODE index = BMI/obstruction/dyspnea/exercise capacity index; $\mathrm{CAT}=\mathrm{COPD}$ assessment test DLCO $=$ diffusing capacity factor of the lung for carbon monoxide; FFMI = fat-free mass index; ICS = inhaled corticosteroids; LABA = long-acting $\beta 2$ agonists; LAMA = long-acting antimuscarinic agents; OXY = Oxymizer; $\mathrm{RV}=$ residual volume; TLC $=$ total lung capacity.

$* \mathrm{p}<0.05$ significantly different to $\mathrm{PaO}_{2}$ at rest breathing $\mathrm{O}_{2}$ via the CNC.

In total, 43 patients completed all test procedures and were finally analyzed. Baseline characteristics of the study population are shown in table 1.

Patients were able to significantly increase their endurance time during the CWRT by $92 \mathrm{~s}(95 \%$ CI 32-152, $\mathrm{p}=$ 0.003) when using the Oxymizer instead of a CNC (fig. 2), and the average $\mathrm{O}_{2}$ flow rate was $3.6 \pm 1.3$ liters $/ \mathrm{min}$. Ox- 


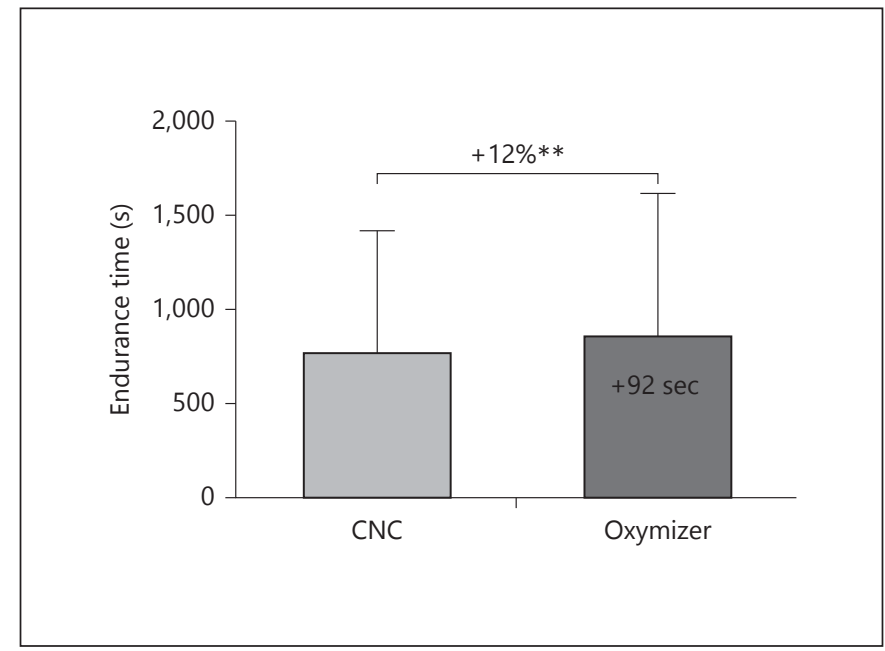

Fig. 2. Endurance time during CWRT in 43 patients with COPD using a CNC or the Oxymizer $(* * \mathrm{p}<0.01)$.

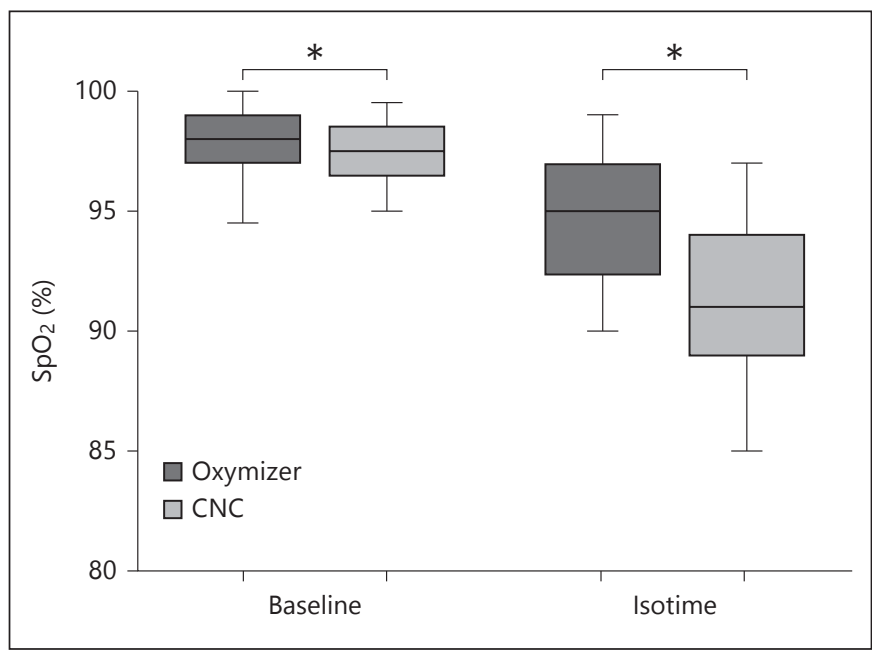

Fig. 3. $\mathrm{SpO}_{2}$ at rest (baseline) before the CWRT and at isotime in 43 COPD patients using $\mathrm{O}_{2}$ application with the Oxymizer or a $\mathrm{CNC}(* \mathrm{p}<0.05)$.

Table 2. Changes in outcomes during CWRT with the use of a CNC or the Oxymizer

\begin{tabular}{|c|c|c|c|c|c|}
\hline & $\begin{array}{l}\mathrm{CNC} \\
(\mathrm{n}=43)\end{array}$ & $\begin{array}{l}\text { Oxymizer } \\
(\mathrm{n}=43)\end{array}$ & $\begin{array}{l}\text { Difference } \\
(95 \% \mathrm{CI})\end{array}$ & $\mathrm{p}$ & $\begin{array}{l}\text { Estimated effect } \\
\text { size (Cohen's d } d^{\text {a }} \text { (Cohe }\end{array}$ \\
\hline \multicolumn{6}{|l|}{ Primary outcome } \\
\hline \multicolumn{6}{|l|}{ Secondary outcomes } \\
\hline HR at rest before CWRT, bpm & $86 \pm 11$ & $86 \pm 13$ & $0(-2-2)$ & 0.933 & 0.00 \\
\hline $\mathrm{SpO}_{2}$ at rest before CWRT, \% & $97.3 \pm 1.7$ & $97.8 \pm 1.6$ & $0.5(-0.8-0.8)$ & 0.017 & 0.50 \\
\hline $\mathrm{SpO}_{2}$ at isotime, $\%$ & $90.4 \pm 5.3$ & $93.5 \pm 5.4$ & $2.5(0.0-5.1)$ & 0.027 & 0.54 \\
\hline $\mathrm{SpO}_{2}$ at end of CWRT, \% & $90.3 \pm 5.3$ & $91.0 \pm 6.2$ & $0.7(0.1-1.4)$ & 0.070 & 0.18 \\
\hline $\mathrm{PaO}_{2}$ at rest before CWRT, $\mathrm{mm} \mathrm{Hg}$ & $72.5 \pm 14.3$ & $78.1 \pm 18.0$ & $5.6(0.6-10.5)$ & 0.029 & 0.31 \\
\hline $\mathrm{PaO}_{2}$ at end of CWRT, $\mathrm{mm} \mathrm{Hg}$ & $61.5 \pm 10.0$ & $64.8 \pm 11.4$ & $3.3(1.6-4.9)$ & $<0.0001$ & 0.29 \\
\hline $\mathrm{PaCO}_{2}$ at rest before CWRT, mm Hg & $38.7 \pm 9.0$ & $38.5 \pm 8.6$ & $-0.2(-2.4-2.0)$ & 0.819 & 0.00 \\
\hline Leg fatigue at end of CWRT, Borg scale & $6.8 \pm 1.9$ & $6.7 \pm 2.0$ & $-0.1(-0.5-0.2)$ & 0.433 & 0.00 \\
\hline
\end{tabular}

Values are mean \pm SD unless otherwise stated. bpm = Beats per min; HR = heart rate.

${ }^{\text {a }} 0.2=$ small effect size, $0.4=$ medium effect size, $0.8=$ large effect size.

ygenation was also higher with the Oxymizer at rest $\left(\mathrm{PaO}_{2}\right.$ $78.1 \pm 18.0$ vs. $72.5 \pm 14.3 \mathrm{~mm} \mathrm{Hg}, \mathrm{p}=0.029)$, at isotime $\left(\mathrm{SpO}_{2} 93.5 \pm 5.4\right.$ vs. $90.4 \pm 5.3 \%, \mathrm{p}=0.027$; fig. 3$)$ and at the end of the CWRT $\left(\mathrm{PaO}_{2} 64.8 \pm 11.4\right.$ vs. $61.5 \pm 10.0$ $\mathrm{mm} \mathrm{Hg}, \mathrm{p}<0.0001)$. However, there was no significant difference at rest or at the peak of CWRT regarding heart rate, $\mathrm{pPaCO}_{2}$, symptoms of dyspnea or leg fatigue between the two $\mathrm{O}_{2}$ application forms (table 2).

For a subgroup analysis, we classified the patients into 4 groups regarding their $\mathrm{O}_{2}$ flow rates $(2,3,4$ or $5-6$ li- 
Table 3. Differences in outcomes of CWRTs in 'O $\mathrm{O}_{2}$-Lowflower' and ' $\mathrm{O}_{2}$-Highflower' patients using a CNC or the Oxymizer

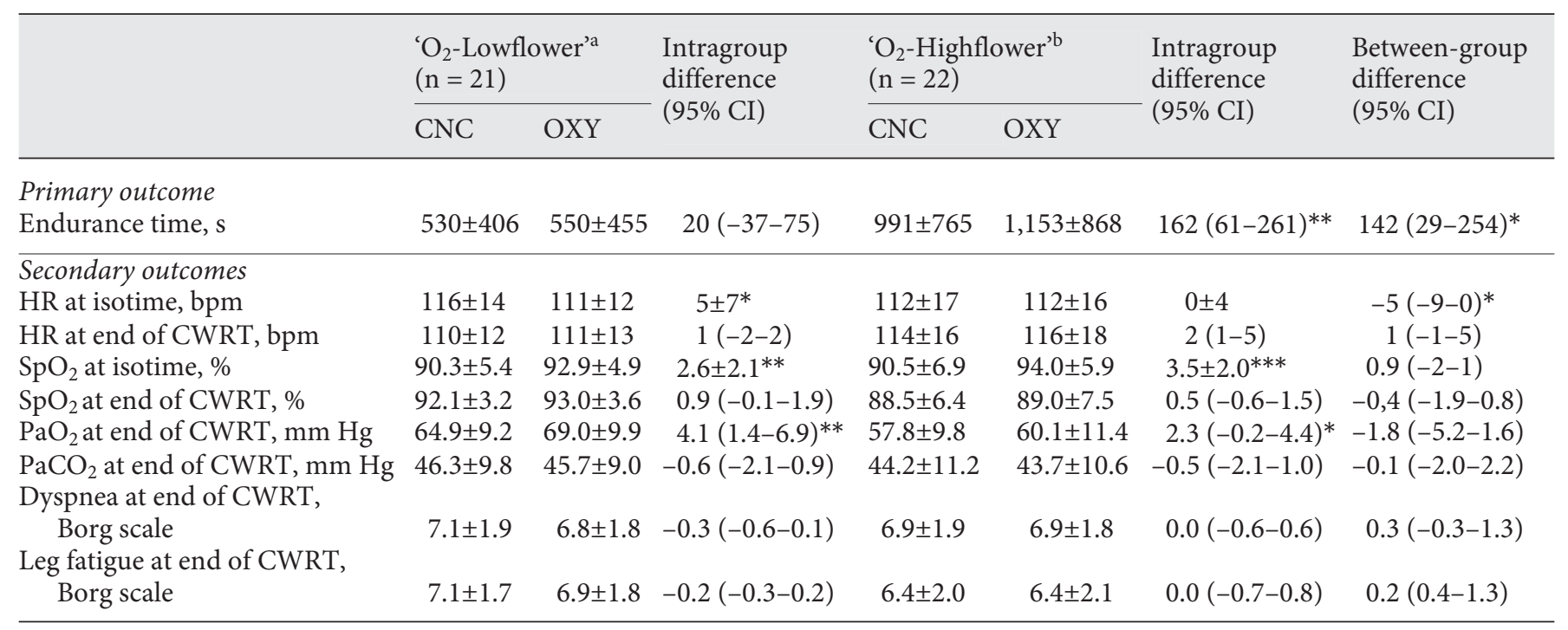

Values are means \pm SD unless otherwise stated. $\mathrm{bpm}=$ Beats per min; HR $=$ heart rate. ${ }^{*} \mathrm{p}<0.05,{ }^{* *} \mathrm{p}<0.01,{ }^{* * *} \mathrm{p}<0.001$.

a $2-3$ liters/min; ${ }^{\text {b }} 4-6$ liters/min.

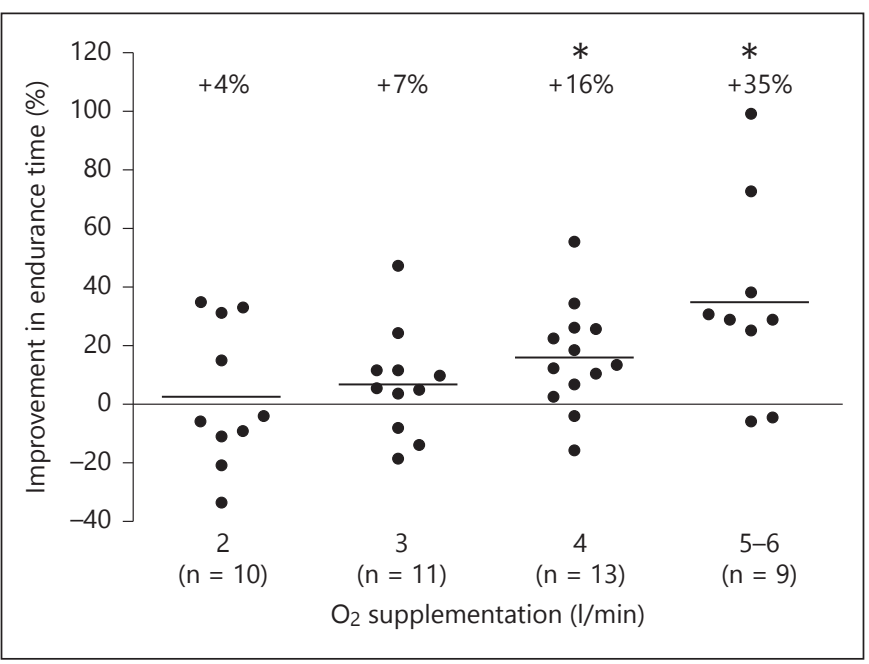

Fig. 4. Additional benefit of the Oxymizer on endurance time during the CWRT in comparison to with a CNC in 43 COPD patients depending on their individual amount of $\mathrm{O}_{2}$ supplementation in liters/min $\left({ }^{*} \mathrm{p}<0.05\right)$.

ters/min). Figure 4 shows that the probability to increase endurance capacity by using the Oxymizer was greater in patients with a higher demand for $\mathrm{O}_{2}(\mathrm{r}=0.427, \mathrm{p}=$ $0.002)$. Patients were then categorized into 2 groups: ' $\mathrm{O}_{2}$ Lowflower' (needing 2-3 liters $/ \mathrm{min}$ ) and ' $\mathrm{O}_{2}$-Highflower' (needing 4-6 liters/min; for patient characteristics see online suppl. table 1). Patients classified as ' $\mathrm{O}_{2}$-Highflower' significantly improved their endurance time by 162 s $(95 \%$ CI 61-261 s, p < 0.01) when using the Oxymizer. In contrast, ' $\mathrm{O}_{2}$-Lowflower' patients were not able to improve their endurance time with the Oxymizer (table 3). Nevertheless, at the end of the CWRT, the Oxymizer had significantly increased $\mathrm{PaO}_{2}$ in all patients independently of low or high $\mathrm{O}_{2}$ flow rates (table 3).

No adverse event or any other unexpected incident occurred during the study.

\section{Discussion}

In this study, patients were able to increase endurance time during the CWRT significantly by $12 \%$ when using the Oxymizer instead of a CNC. However, this is equivalent to a benefit of $92 \mathrm{~s}$ which is still below the expected MID of $105 \mathrm{~s}$ [22]. The superiority of breathing $\mathrm{O}_{2}$ via the Oxymizer was consistent between test 1 and test 2 as well as between test 3 and test 4 (see online suppl. fig. 2). Dividing the study population into ' $\mathrm{O}_{2}$-Highflowers' and ' $\mathrm{O}_{2}$-Lowflowers', we found that only ' $\mathrm{O}_{2}$-Highflower' patients were able to improve endurance time to a clinically relevant extent (by 162 s) by using the Oxymizer. Studies that have investigated the effects of a bronchodilator inhalation therapy (over 3-4 weeks) versus placebo report- 
ed improvements of 67 [23], 93 [24] and 111 [25] s in the exercise endurance time. That a simple device like the $\mathrm{Ox}$ ymizer can improve exercise endurance to a similar or even larger extent than bronchodilator inhalation is an interesting finding. Especially in very disabled patients with advanced COPD and the need for LTOT, the Oxymizer could be an easy and safe approach to improve exercise endurance and oxygenation. Oxygenation was significantly higher with the Oxymizer than with CNC at isotime. Since isotime can be seen as a reliable parameter in interventional trials, this represents a worthwhile finding of this study. Furthermore, at peak exercise of the CWRT, hypoxemia $\left(\mathrm{PaO}_{2}<60 \mathrm{~mm} \mathrm{Hg}\right)$ was prevalent in $18 / 43$ individuals (42\%) when using CNC and in only $12 / 43(28 \%)$ when using the Oxymizer.

However, regardless of low or high $\mathrm{O}_{2}$ flow rates, the Oxymizer increased oxygenation at rest and during exercise significantly above the level reached by the CNC. In ' $\mathrm{O}_{2}$-Highflowers', in particular, the Oxymizer was successful in keeping the mean $\mathrm{PaO}_{2}$ level $>60 \mathrm{~mm} \mathrm{Hg}$ upon completion of CWRT, but it dropped below this threshold with CNC. This could reveal a meaningful benefit towards better oxygenation in daily life.

It must be noted that these results were obtained during a cycling task and may therefore not be directly transferred to other activities of daily living. Another point of clinical relevance is whether there is a different response between the two $\mathrm{O}_{2}$ delivery systems regarding symptoms of dyspnea during activity. Although patients cycled longer with the Oxymizer, their dyspnea ratings at peak CWRT were at a comparable level. Unfortunately, we did not record sensations of dyspnea at isotime to support this relevance.

A recently published study by Marti et al. [26] investigated the effects of an Oxymizer versus a CNC in a crossover study design during the 6-minute walking test (6MWT) in 28 patients with COPD (age $66 \pm 9$ years and $\mathrm{FEV}_{1} 31 \pm 11 \%$ pred.). $\mathrm{O}_{2}$ supplementation via Oxymizer and $\mathrm{CNC}$ were similarly effective in correcting exerciseinduced hypoxemia during the $6 \mathrm{MWT}$ in comparison to room air. During the test, an average $\mathrm{SpO}_{2}$ of $\geq 90 \%$ was reached in 86 and $79 \%$ of the patients with the Oxymiser and $\mathrm{CNC}$, respectively. However, use of the Oxymizer did not result in any further increase of 6MWT distance compared to the CNC ( $347 \pm 10$ vs. $352 \pm 11 \mathrm{~m}, \mathrm{p}=$ n.s. $)$. This finding diverges from ours, and may perhaps be explained by the self-paced nature of the $6 \mathrm{MWT}$ in comparison to a CWRT.

Adherence is an aspect that could further complicate the use of an Oxymizer in the 'real life' of patients. Ac- ceptance of the Oxymizer was once investigated in a small study including 21 patients over a 1-month period; a former version of the Oxymizer which was made out of stiffer and less comfortable plastic material than the current one was evaluated [11]. Although patients successfully maintained their $\mathrm{SpO}_{2}$ level despite a 3-fold reduction in the rate of $\mathrm{O}_{2}$ flow, $9 / 21$ patients (43\%) abandoned the Oxymizer due to discomfort.

Our study has several strengths. Firstly, it was adequately powered to detect a clinically relevant difference between the use of a $\mathrm{CNC}$ and the Oxymizer during a CWRT in subjects with COPD. Secondly, the CWRT is an approved, valid method for assessing endurance capacity in patients with COPD with highly significant intraclass correlation coefficients $(\geq 0.85)$ between test and retest ( $p<0.001$ ) [19]. Thirdly, the cross-over design used in this study can be considered a useful strategy for eliminating the potential bias of fatigue or variable daily conditions between the CWRTs.

However, this study also reveals some limitations: the chosen intensity of 70\% of PWR during the CWRTs overall for patients might have been too low as there was a wide range in endurance time. A higher cycling intensity or a more progressive test protocol might have resulted in more homogeneous results. Furthermore, whether a patient's breathing pattern during the CWRTs was via the nose or mouth was not recorded, and so the efficacy of $\mathrm{O}_{2}$ intake was not precisely detectable. We wanted to investigate a 'real life' situation of providing $\mathrm{O}_{2}$ via two different types of nasal cannula. We believe that the differences in influence of the individual breathing pattern may have been neglible.

\section{Conclusions}

To our knowledge, this is the first study which showed that $\mathrm{O}_{2}$ delivery via the Oxymizer is superior to a CNC with regard to improved exercise endurance time and oxygenation (at rest, at isotime and at peak exercise) during cycling in hypoxemic patients with COPD. It seems that patients with $\mathrm{O}_{2}$ flow rates of $\geq 4$ liters/min, in particular, may benefit the most from the use of an Oxymizer during exercise training. Thus, this device may thus be used to improve endurance capacity in very disabled patients. Future studies are needed to evaluate if exercise intensity during endurance training can be further increased and if improvements in exercise capacity are superior when $\mathrm{O}_{2}$ supplementation is provided via an Oxymizer. 


\section{Acknowledgements}

We want to thank Ms. Monika Jell and her staff from the Diagnostic Department at the Schoen Klinik Berchtesgadener Land for their outstanding support.

\section{Financial Disclosure and Conflicts of Interest}

The authors acknowledge that there are no conflicts of interest with any company or organization whose products or services may have influenced this study or manuscript.

\section{References}

1 GOLD Global Strategy of the diagnosis, management, and prevention of chronic obstructive pulmonary disease, updated February 2013. www.goldcopd.org (accessed 03.05.2013).

-2 Koehler U, Hildebrandt O, Jerrentrup L, Koehler KI, Kianinejad P, Sohrabi K, et al: Long-term oxygen therapy (LTOT) - what should physicians, homecare-providers and health insurance companies know? Pneumologie 2014;68:193-198.

3 Nocturnal Oxygen Therapy Trial Group: Continuous or nocturnal oxygen therapy in hypoxemic chronic obstructive lung disease: a clinical trial. Ann Intern Med 1980;93:391-398.

$\checkmark 4$ Report of the Medical Research Council Working Party: Long-term domiciliary oxygen therapy in chronic hypoxic cor pulmonale complicating chronic bronchitis and emphysema. Lancet 1981;1:681-686.

5 Vogiatzis I, Athanasopoulos D, Stratakos G, Garagouni C, Koutsoukou A, Boushel R, et al: Exercise-induced skeletal muscle deoxygenation in O-supplemented COPD patients. Scand J Med Sci Sports 2009;19:364-372.

6 O'Donnell DE, D'Arsigny C, Webb KA: Effects of hyperoxia on ventilatory limitation during exercise in advanced chronic obstructive pulmonary disease. Am J Respir Crit Care Med 2001;163:892-898.

7 Woodcock AA, Gross ER, Geddes DM: Oxygen relieves breathlessness in 'pink puffers'. Lancet 1981;1:907-909.

8 Gloeckl R, Marinov B, Pitta F: Practical recommendations for exercise training in patients with COPD. Eur Respir Rev 2013;22: 178-186.
$>$ Dunne PJ: The clinical impact of new longterm oxygen therapy technology. Respir Care 2009;54:1100-1111.

-10 Arlati S, Rolo J, Micallef E, Sacerdoti C, Brambilla I: A reservoir nasal cannula improves protection given by oxygen during muscular exercise in COPD. Chest 1988;93:1165-1169.

11 Claiborne RA, Paynter DE, Dutt AK, Rowlands JW: Evaluation of the use of an oxygen conservation device in long-term oxygen therapy. Am Rev Respir Dis 1987;136:10951098.

12 Gould GA, Hayhurst MD, Scott W, Flenley DC: Clinical assessment of oxygen conserving devices in chronic bronchitis and emphysema. Thorax 1985;40:820-824.

13 Moore-Gillon JC, George RJ, Geddes DM: An oxygen conserving nasal cannula. Thorax 1985;40:817-819.

$\checkmark 14$ Collard P, Wautelet F, Delwiche JP, Prignot J, Dubois P: Improvement of oxygen delivery in severe hypoxaemia by a reservoir cannula Eur Respir J 1989;2:778-781

15 Tiep BL, Burns M, Hererra J: A new pendant oxygen-conserving cannula which allows pursed-lips breathing. Chest 1989;95:857860.

16 Hagarty EM, Skorodin MS, Stiers WM, Mamdani MB, Jessen JA, Belingon EC: Performance of a reservoir nasal cannula (Oxymizer) during sleep in hypoxemic patients with COPD. Chest 1993;103:1129-1134.

$\checkmark 17$ ATS ACCP: Statement on cardiopulmonary exercise testing. Am J Respir Crit Care Med 2003;167:211-277.

18 Gloeckl R, Halle M, Kenn K: Interval versus continuous training in lung transplant candidates: a randomized trial. J Heart Lung Transplant 2012;31:934-941.
19 van 't Hul A, Gosselink R, Kwakkel G: Constant-load cycle endurance performance: testretest reliability and validity in patients with COPD. J Cardiopulm Rehabil 2003;23:143150.

20 Borg GA: Psychophysical bases of perceived exertion. Med Sci Sports Exerc 1982;14:377381.

21 Miller MR, Hankinson J, Brusasco V, Burgos F, Casaburi R, Coates A, et al: Standardisation of spirometry. Eur Respir J 2005;26:319-338.

-22 Casaburi R: Factors determining constant work rate exercise tolerance in COPD and their role in dictating the minimal clinically important difference in response to interventions. COPD 2005;2:131-136.

23 O'Donnell DE, Fluge T, Gerken F, Hamilton A, Webb K, Aguilaniu B, et al: Effects of tiotropium on lung hyperinflation, dyspnoea and exercise tolerance in COPD. Eur Respir J 2004;23:832-840.

24 Magnussen H, Paggiaro P, Schmidt H, Kesten S, Metzdorf N, Maltais F: Effect of combination treatment on lung volumes and exercise endurance time in COPD. Respir Med 2012; 106:1413-1420.

25 O’Donnell DE, Casaburi R, Vincken W, Puente-Maestu L, Swales J, Lawrence D, et al: Effect of indacaterol on exercise endurance and lung hyperinflation in COPD. Respir Med 2011;105:1030-1036.

26 Marti S, Pajares V, Morante F, Ramon MA, Lara J, Ferrer J, et al: Are oxygen-conserving devices effective for correcting exercise hypoxemia? Respir Care 2013;58:1606-1613. 